\title{
PENAMBAHAN BUBUR LABU KUNING TERHADAP PREFERENSI SAUS TOMAT-LABU KUNING
}

\author{
Seveline \\ Ilmu dan Teknologi Pangan, Fakultas Bioindustri, Universitas Trilogi \\ Kalibata - Jakarta Selatan \\ seveline@universitas-trilogi.ac.id
}

\begin{abstract}
Tomato ketchup is a product favored by the people of Indonesia. The use of pumpkin as filler substance in the production of tomato ketchup is performed as an alternative to conventional tomato ketchup filler substance. This study aims to determine the right balance between the tomato puree and pumpkin puree to produce a tomato ketchup that can be accepted by consumers, without addition of coloring agents and other food additives. The results showed that the quantity of tomato puree and pumpkin puree in proportion of 85 and 15 produces the best tomato ketchup and has the same characteristics as the standard and is preferred by the panelists, with a viscosity of $40300 \mathrm{cps}$, the water content of $61.53 \%$ and $\mathrm{pH}$ of 3.87 .
\end{abstract}

Keywords: tomato, pumpkin, tomato ketchup, physical and chemical analysis, organoleptic test

\section{PENDAHULUAN}

Indonesia merupakan negara penghasil sayuran dan buahan yang cukup potensial dikembangkan. Untuk itu perlu adanya diversifikasi produk olahan sayur dan buahbuahan agar sejalan dengan usaha perbaikan gizi masyarakat, pemenuhan permintaan pasar dalam negeri serta pengurangan impor dan penambahan ekspor untuk memperbesar devisa negara. Rata-rata hasil panen tomat dari tahun 2003 sampai dengan 2014 di Indonesia sebesar 785.243,083 ton (Badan Pusat Statistik, 2016). Hasil ini cukup besar sehingga perlu diusahakan pemanfaatan dari buah tomat tersebut.

Secara botanis tomat termasuk family Solanaceae, satu family dengan kentang, terung dan cabai. Ditinjau dari kepentingan kebutuhan zat gizi manusia, tomat merupakan sumber vitamin khususnya vitamin A, B dan C dan beberapa mineral serta sumber serat kasar (Luh dan Woodroof, 1988). Tomat (Solanum lycopersicum) merupakan salah satu komoditas buah sayur, didasarkan atas kebiasaan dan kesepakatan dimana komoditas ini digunakan sebagai nasi. Menurut SK Menteri Pertanian Nomor : 511/Kpts/PD310/9/2006, tomat termasuk ke dalam tanaman hortikultura. Permintaan tomat untuk ketersediaan lainnya meliputi penggunaan untuk industri pangan, obatobatan dan kosmetik (Kementerian Pertanian, 2012). Jenis produk olahan tomat di industri pangan antara lain saus tomat, sari tomat, jelly drink tomat, yoghurt tomat, sirup tomat, puree (bubur) tomat, selai tomat, permen jelly tomat, dan manisan tomat (Dewanti dkk., 2010).

Saus tomat sudah dikenal baik sebagai hasil olahan yang digunakan sebagai penyedap masakan atau penambah selera makan. Pada pembuatan saus tomat diperlukan tomat sebagai bahan utama dan bahan pengisi untuk menaikkan kekentalannya. Saus tomat dapat dibuat dengan penambahan bahan pengisi. Bahan pengisi yang digunakan banyak yang menggunakan pati, seperti tepung tapioka dan maizena tetapi dapat juga diguanakan bahan lain seperti wortel, ubi jalar, papaya, singkong dan labu kuning (Ginting dkk.,2007; Alam dkk., 2009).

Labu kuning (Cucurbita moschata) dapat dijadikan bahan pengisi karena memiliki daging buah yang tebal, rasa gurih, manis, berdaging halus dan padat. Buah labu kuning berbentuk bulat pipih, lonjong, atau panjang dengan banyak alur (15-30 alur). 
Warna daging yang berwarna kuning menandakan kandungan karoten dan xantofil yang relatif tinggi (Luh dan Woodroof, 1988). Labu kuning yang memiliki kandungan karbohidrat yang tinggi dapat digunakan untuk menggantikan bahan pengisi dari saus tomat.

\section{METODE}

\section{Bahan dan Alat}

Bahan yang digunakan adalah tomat apel (Solanum lycopersicum) kualitas B.S (below standard) berumur 60 hari-75 hari, seluruh permukaan kulit berwarna merah (red). Bahan pengisi yang digunakan labu kuning lokal (Cucurbita moschata) jenis bokor yang berumur 3-4 bulan dengan kulit berwarna hijau.

Bahan-bahan lain berupa gula pasir, asam asetat, garam halus, bawang putih dan rempah-rempah (kayu manis, merica, kembang pala dan cabai bubuk dalam bentuk yang sudah dihaluskan atau bubuk) didapat dari pasar tradisional.

Alat-alat yang digunakan blender, saringan, panci, kain saring, pengaduk kayu, sendok, botol dengan tutupnya, pisau, timbangan, waskom, termometer, neraca analitik, cawan porselen, desikator, gelas ukur, viskosimeter, $\mathrm{pH}$ meter serta alat gelas lainnya.

Metode penelitian dengan metode percobaan menggunakan Rancangan Acak Kelompok (RAK). Percobaan terdiri dari 5 perlakuan dan diulang 5 kali. Kelima perlakuan tersebut adalah imbangan bubur tomat dengan bubur waluh sebagai pengisi. Perlakuan $\mathrm{A}=70$ bagian bubur tomat : 30 bagian bubur waluh; perlakuan $\mathrm{B}=75$ bagian bubur tomat : 25 bagian bubur waluh; perlakuan $\mathrm{C}=80$ bagian bubur tomat : 20 bagian bubur waluh: perlakuan D 85 bagian bubur tomat : 15 bagian bubur waluh; perlakuan $\mathrm{E}=100$ bagian bubur tomat (kontrol).

\section{Pelaksanaan}

Untuk botol disterilkan terlebih dahulu, kemudian dilakukan penyiapan bahan. Pembuatan bubur tomat dengan cara dibersihkan, diblansing dan diblender, bubur tomat disaring. Pembuatan bubur waluh dengan cara dibersihkan, dikukus kemudian diblender dan ditimbang. Penimbangan bumbu (kayu manis, merica, kembang pala, cabai bubuk, bawang putih yang seluruhnya telah dihancurkan), gula, garam dan cuka. Untuk setiap 1000 gram bubur tomat digunakan 115 gram gula pasir, 29 gram bawang putih, 15 gram merica, 1,5 gram kayu manis, 1,5 gram cabai bubuk, 1 gram kembang pala, 10 gram garam dapur dan larutan cuka dapur konsentrasi 5\% sebanyak $70 \mathrm{~mL}$. Semua bumbu dimasukkan ke dalam kantung saring dan siap dicampur dan dimasak bersama bubur tomat dan bubur waluh. Campurkan kedua bubur dan bumbu kemudian dimasak sampai suhu $80-90^{\circ} \mathrm{C}$ sambil terus diaduk agar tidak mengerak, sampai kekentalan saus yang diinginkan tercapai (volume akhir menjadi sepertiga volume awal). Kemudian dilakukan pengisian pada botol yang telah steril, dan dalam keadaan hangat ditutup. Pengamatan dilakukan pada sifat fisik (viskositas) dan sifat kimia (kadar air dan derajat keasaman) serta uji organoleptik dengan uji hedonik untuk mengetahui tingkat kesukaan terhadap warna, aroma dan rasa saus. Semua uji dilakukan duplo, dan diuji statistik dengan uji Duncan pada taraf nyata $5 \%$.

\section{HASIL DAN PEMBAHASAN}

\section{Pengamatan Sifat Fisik}

\section{Viskositas Saus Tomat}

Viskositas untuk saus tomat dapat dilihat pada Tabel 1. Viskositas berhubungan dengan bentuk cairan atau nilai kekentalan. Hasil analisis viskositas saus tomat ternyata viskositas dari perlakuan A sampai E berkisar antara 50072 sampai dengan 23016 cps. Untuk perlakuan A berbeda dengan B, C dan kedua perlakuan tersebut berbeda dengan $\mathrm{D}$ dan berbeda dengan perlakuan $\mathrm{E}$ yaitu tanpa penambahan bubur waluh.

Tabel 1. Nilai Viskositas Saus Tomat (cps)

\begin{tabular}{|l|l|l|}
\hline Perlakuan & Viskositas & Keterangan \\
\hline A (70:30) & 50072 & a \\
\hline B (75:25) & 42056 & ab \\
\hline C $(80: 20)$ & 42568 & ab \\
\hline D $(85: 15)$ & 40300 & b \\
\hline E (kontrol) & 23016 & $\mathrm{c}$ \\
\hline
\end{tabular}


Ket: rata-rata perlakuan yang ditandai dengan huruf yang sama, tidak berbeda nyata menurut Uji Duncan pada taraf nyata $5 \%$

Viskositas saus dari perlakuan E tanpa penambahan bubur waluh paling rendah atau paling cair, dan perlakuan dengan penambahan bubur waluh paling banyak menghasilkan saus yang paling kental. Seperti diketahui bahwa saus tomat Heinz berkisar 50.000 cps (centipoise) sehingga untuk data diatas nilainya masih tidak jauh berbeda pada saus tomat umumnya (viscosity chart, http://www.research-equipment.com/viscosity \%20chart.html diakses 16/2/2016). Pada penelitian Bayod et al. (2008) menyatakan bahwa viskositas saus tomat yang beredar di pasaran umumnya adalah sekitar 50.000 sampai dengan 26.000 cps. Viskositas merupakan sifat dari cairan yaitu kecepatan aliran dan tekanan aliran. Tekanan merupakan tenaga yang dikenakan pada suatu bahan dan besarnya tenaga ini sama dengan massa bahan tersebut dikalikan kecepatan aliran. Hal ini dipengaruhi oleh sifat cairan itu sendiri, jika kecepatan aliran suatu cairan sebanding dengan tekanan yang diberikan maka aliran tersebut bersifat Newtonian dan jika sebaliknya bersifat non-Newtonian. Saus tomat termasuk ke dalam non-Newtonian yang artinya tergantung pada suhu dan shear rate.

\section{Pengamatan Sifat Kimia}

\section{Kadar air}

Kadar air merupakan komponen yang penting dalam bahan makanan karena air dapat mempengaruhi penampakan, tekstur serta cita rasa makanan. Hasil analisis statistik kadar air saus tomat dapat dilihat pada Tabel 2.

Tabel 2. Hasil Analisis Kadar Air Saus Tomat (\%)

\begin{tabular}{|l|l|l|}
\hline Perlakuan & Kadar Air & Keterangan \\
\hline A (70:30) & 68,85 & a \\
\hline B (75:25) & 66,14 & a \\
\hline C (80:20) & 66,69 & a \\
\hline D (85:15) & 61,53 & b \\
\hline E (kontrol) & 57,33 & c \\
\hline
\end{tabular}

Ket: Rata-rata perlakuan yang ditandai dengan huruf yang sama, tidak berbeda nyata menurut Uji Duncan pada taraf nyata $5 \%$

Kadar air saus tomat untuk perlakuan A, B, C berbeda nyata dengan perlakuan D dan dengan perlakuan E. Kadar air ditentukan oleh jumlah bahan utama yang digunakan selama proses pengolahan. Bila kandungan air pada bahan tinggi maka padatan pada bahan tersebut sedikit. Penambahan labu kuning yang semakin banyak pada saus tomat maka akan menghasilkan kadar air yang semakin tinggi. Kadar air labu kuning cukup tinggi, pada labu kuning didapat kadar air sebesar $83,27 \%$ sedangkan pada pasta labu kuning didapat 90,57\% (Ikhsani dan Susanto, 2015) Sedangkan pada penelitian Alam et al. (2009) pada penggunaan CMC pada saus tomat, kadar air bubur tomat sebesar $93.40 \%$ dan ketika menjadi saus tomat berkisar $73,35 \%$ sampai dengan $82,93 \%$. Labu kuning dan tomat ternyata memiliki kadar air yang cukup tinggi, sehingga ketika bahan tersebut dicampur maka menghasilkan kadar air yang tinggi pula. Kadar air tersebut tidak jauh berbeda dengan hasil pembuatan saus dengan penambahan ubi jalar yaitu berkisar antara 77\% sampai dengan 78\% (Ginting dkk., 2007).

\section{Derajat Keasaman (pH)}

Derajat keasaman $(\mathrm{pH})$ merupakan indikator keasaman, hasil $\mathrm{pH}$ dapat dilihat pada tabel 3. Pada perlakuan A berbeda dengan perlakuan $\mathrm{B}$ dan perlakuan $\mathrm{B}$ berbeda dengan perlakuan $\mathrm{C}$ dan perlakuan $\mathrm{C}$ berbeda dengan perlakuan $\mathrm{D}$ dan $\mathrm{E}$. Perlakuan A merupakan $\mathrm{pH}$ yang paling tinggi dan perlakuan E (kontrol) memiliki perlakuan paling rendah. Derajat keasaman $(\mathrm{pH})$ adalah keasaman efektif yaitu tingkat keasaman yang menunjukkan aktivitas ion hidrogen dan aktivitas ion tersebut sangat dipengaruhi oleh sifat asam, suhu, pengenceran dan bahanbahan lain yang terlarut. Pada penelitian Alam et al.(2009) saus tomat yang dihasilkan dengan penambahan pati dan CMC masingmasing menghasilkan $\mathrm{pH} 4.05$ sampai 4.09 dan 4.10 sampai dengan 4.22. Tidak jauh berbeda pada pembuatan saus tomat dengan 
menggunakan ubi jalar dalam penelitian Ginting dkk. (2007), pH yang didapat berkisar antara 4,75 sampai 4,70. pH dari saus tomat dan penambahan labu kuning ini tidak jauh berbeda semakin sedikit penambahan labu kuning maka $\mathrm{pH}$ akan semakin rendah yang menandakan bahwa saus akan semakin asam. Produk saus tomat dipengaruhi oleh kandungan asam organik pada tomat. Menurut Yilmaz (2001) asam-asam organik merupakan asam yang paling banyak terkandung dalam tomat segar seperti asam sitrat dan asam malat. Penelitian Gancedo dan Luh (1986) selain sitrat dan malat terdapat pula asam oksalat, galakturonat, dan pyrrolidonekarboksilat pada jus tomat kalengan sedangkan pada saus tomat olahan terdapat asam sitrat dan asam malat (Lehkoživová et al., 2009).

Tabel 3. Hasil Analisis pH Saus Tomat

\begin{tabular}{|l|l|l|}
\hline Perlakuan & $\mathrm{pH}$ & Keterangan \\
\hline $\mathrm{A}(70: 30)$ & 4,07 & $\mathrm{a}$ \\
\hline $\mathrm{B}(75: 25)$ & 4,01 & $\mathrm{ab}$ \\
\hline $\mathrm{C}(80: 20)$ & 3,93 & $\mathrm{bc}$ \\
\hline $\mathrm{D}(85: 15)$ & 3,87 & $\mathrm{c}$ \\
\hline E (kontrol) & 3,86 & $\mathrm{c}$ \\
\hline
\end{tabular}

Ket: Rata-rata perlakuan yang ditandai dengan huruf yang sama, tidak berbeda nyata menurut Uji Duncan pada taraf nyata $5 \%$

\section{Hasil Uji Hedonik Terhadap Warna, Aroma dan Rasa Saus Tomat}

Uji hedonik dilakukan untuk warna, aroma dan rasa saus. Dari perlakuan A sampai dengan $\mathrm{D}$ ternyata perbedaan hanya pada warna saja yang berbeda nyata, sedangkan untuk aroma dan rasa tidak berbeda nyata.

Warna merupakan faktor yang menentukan mutu, juga dapat digunakan sebagai baik tidaknya cara pencampuran atau cara pengolahan pangan. Warna saus tomat yang baik sesuai dengan mutu standar SNI 013546-1994 adalah warna khas tomat yaitu merah. Tomat yang memiliki warna khas merah dan labu kuning memiliki warna kuning merah, sehingga hasil saus yang didapat dengan semakin banyaknya penambahan labu kuning yang maka akan mengubah warna dari saus tomat tersebut menjadi merah kekuningan walaupun warna merah masih tetap dominan. Untuk warna perlakuan D disukai sedangkan perlakuan lainnya agak disukai.

Tabel 4. Tingkat Kesukaan terhadap Warna, Aroma dan Rasa Saus Tomat

\begin{tabular}{|l|l|l|l|}
\hline \multirow{2}{*}{ Perlakuan } & \multicolumn{3}{|c|}{ Tingkat Kesukaan Terhadap } \\
\cline { 2 - 4 } & Warna & Aroma & Rasa \\
\hline $\mathrm{A}(70: 30)$ & $2,69 \mathrm{~b}$ & $2,96 \mathrm{a}$ & $2,75 \mathrm{a}$ \\
\hline $\mathrm{B}(75: 25)$ & $2,85 \mathrm{~b}$ & $3,03 \mathrm{a}$ & $3,13 \mathrm{a}$ \\
\hline $\mathrm{C}(80: 20)$ & $2,92 \mathrm{~b}$ & $3,33 \mathrm{a}$ & $3,13 \mathrm{a}$ \\
\hline $\mathrm{D}(85: 15)$ & $3,69 \mathrm{a}$ & $3,35 \mathrm{a}$ & $3,37 \mathrm{a}$ \\
\hline E (kontrol) & $3,93 \mathrm{a}$ & $3,49 \mathrm{a}$ & $3,27 \mathrm{a}$ \\
\hline
\end{tabular}

Ket: Rata-rata perlakuan yang ditandai dengan huruf yang sama, tidak berbeda nyata menurut Uji Duncan pada taraf nyata $5 \%$

Untuk aroma dan rasa ternyata tidak berbeda nyata, artinya untuk semua imbangan dan kontrol disukai oleh panelis. Hal ini menandakan bahwa produk saus tomat dari aroma dan rasanya disukai hanya saja warnanya yang agak berbeda.

\section{KESIMPULAN}

Saus tomat dengan penambahan labu kuning dengan rasio $85: 15$ merupakan saus yang paling disukai oleh panelis dengan viskositas, kadar air dan $\mathrm{pH}$. Penggunaan labu kuning tidak menimbulkan perubahan yang nyata dalam aroma dan rasa hanya pada warna saja.

\section{SARAN}

Perlu dilakukan uji pembanding untuk produk saus tersebut, sehingga bisa diketahui apakah produk tersebut menyerupai saus tomat yang beredar di pasaran. Selain itu bisa diuji kandungan bahan lainnya seperti karoten, asam organik atau zat flavonol lainnya, sehingga saus ini walaupun ditambahkan labu kuning tetapi memiliki antioksidan yang tinggi.

\section{DAFTAR PUSTAKA}

Alam, M.D., Ahmed, M., Akter, M.S., Islam, N. dan Eun J. 2009. Effect of Carboxymethylcellulose and Starch as Thickening Agents on the Quality of 
Tomato Ketchup. Pakistan Journal of Nutr 8(8) : 1144-1149.

Bayod,E., Willers, E.P. dan Tornberg, E. 2008. Rheological and structural characterization of tomato paste and its influence on the quality of ketchup. LWT Food Sci. and Tech. 41:12891300

Dewanti T.W., Rukmi, W.D., Nurcholis, M. dan Maligan, J.M. 2010. Aneka Produk Olahan Tomat dan Cabe-Pengabdian Masyarakat. Jurusan Teknologi Hasil Pertanian. Fateta. Universitas Brawijaya

Gancedo, M.C. dan Luh, 1986. HPLC Analysis of Organic Acids and Sugars in Tomato Juice. Journal Food Science 51(3) : 571-573.

Ginting,E., Prasetiaswati N. dan Widodo, Y. 2007 Peningkatan Daya Guna dan Nilai Tambah Ubi Jalar Berukuran Kecil melalui Pengolahan Menjadi Saos dan Selai. Iptek Tanaman Pangan Vol. 2 (1) : 110-122.

Ikhsani, A.Y. dan Susanto, W.H. 2015.Pengaruh Proporsi Pasta Labu Kuning dan Cabai Rawit serta
Konsentrasi Ekstrak Rosella Merah Terhadap Sifat Fisik dan Kimia Organoletpik Saus Labu Kuning Pedas. Jurnal Pangan dan Agroindustri 3(2) : 499-510

Lehkoživová, J., Karovičová, J. dan Kohajdová, Z. 2009. The Quality and Authenticity Markers of Tomato Ketchup. Acta Chimica Slovaca, Vol.2, No.2, 2009, 88 - 96

Luh, B.S. dan Woodroof, J.G. 1988. Commercial Fruit and Vegetable Processing. Avi Publishing. New York.

Produksi Tanaman Hortikultura (www.bps.go.id). Tanggal akses 16-22016

Pusat Data dan Sistem Informasi Pertanian. 2012. Outlook Komoditi Tomat. Sektretariat Jenderal Kementerian Pertanian.

Viscosity chart. www.researchequipment.com/viscosity $\% 20$ chart.htm 1. Tanggal akses 16/2/2016

Yilmaz, E. 2001. The Chemistry of Fresh Tomato Flavor. Turk J Agric For 25 : 149-155 